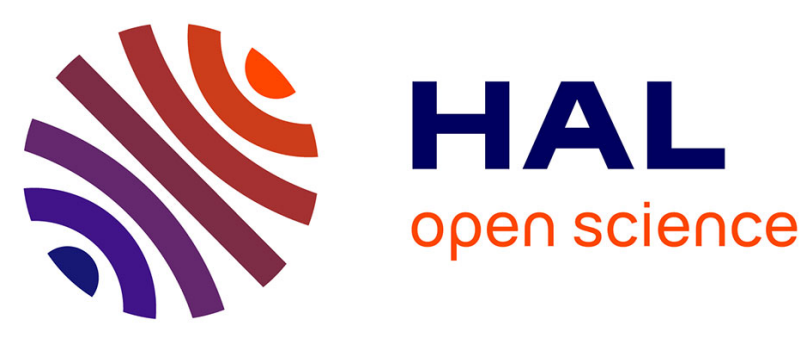

\title{
Open Quotation Revisited
}

François Recanati

\section{To cite this version:}

François Recanati. Open Quotation Revisited. Philosophical Perspectives, 2009, 22, pp.399-427. ijn_00352817

\section{HAL Id: ijn_00352817 \\ https://hal.science/ijn_00352817}

Submitted on 13 Jan 2009

HAL is a multi-disciplinary open access archive for the deposit and dissemination of scientific research documents, whether they are published or not. The documents may come from teaching and research institutions in France or abroad, or from public or private research centers.
L'archive ouverte pluridisciplinaire HAL, est destinée au dépôt et à la diffusion de documents scientifiques de niveau recherche, publiés ou non, émanant des établissements d'enseignement et de recherche français ou étrangers, des laboratoires publics ou privés. 


\title{
Open quotation revisited
}

\author{
François Recanati \\ Institut Jean-Nicod (Paris) \& Arché (St Andrews)
}

Sometimes, by putting words within quotation marks, we build an expression which refers to the words within the quotation marks. Examples are provided in (1) and (2):

(1) 'Very' is a four-letter word

(2) He said 'I am fed up with all this', and slammed the door.

Even though 'very' is an adverb and 'I am fed up with all this' a sentence, the expressions constructed by putting them within quotation marks play the grammatical role of a 'singular term' in the sentences in which those quotations occur. Because they go where singular terms can go, quotations have been analysed as singular terms. Some theorists see them as a variety of proper names, others as demonstratives, still others as definite descriptions.

In 'Open Quotation' I have argued that it is a mistake to build a general theory of quotation on such examples, since they are not representative of the entire category of cases. (1) and (2) are instances of 'closed' quotation. Closed quotations are singular terms referring to the enclosed material, but not all quotations are like that. In 'open quotation', just as in closed quotation, words are ostensively displayed, but their syntactic and semantic type remains unaffected - the quotation is not grammatically recruited as a singular term. Compare (2) with (3) :

(3) 'I am fed up with all this'. Don't you have anything more constructive to say ?

In (2) the words 'I am fed up with all this' fill a slot in the sentence-frame 'He said _, and slammed the door'. The quotation serves as a grammatical object for the transitive verb 'say'. No such thing happens in (3). Yet (2) and (3) have a lot in common: in both cases the words 'I am fed up with all this' are ostensively displayed (rather than used in the normal way). On my view, closed quotations are like open quotations, but they are distinguished by an additional feature : their grammatical enrolment as singular terms designating the enclosed materials. Interesting though it is, this additional feature is too specific to be the centerpiece in the general theory of quotation, and more attention should be paid to open quotation than has been the case so far (or than had been the case when I wrote 'Open Quotation'; for the situation has changed, as witnessed by the special issue which the Belgian Journal of Linguistics devoted to this topic a few years ago). ${ }^{1}$

A closed quotation refers to the enclosed expression, or, more precisely, to some type which the displayed token instantiates. That is the content, or semantic contribution, of the closed quotation. The major difficulty which closed quotation raises for compositional semantics is that the content of the enclosed words does not seem to be relevant to the content of the quotation; indeed, even if the enclosed words are meaningless and lack content, the quotation will keep its referential value (it will still refer to the enclosed words). Yet

\footnotetext{
${ }^{1}$ See De Brabanter (ed.) 2005. This paper is my reaction to the articles discussing open quotation in that issue of the Belgian Journal of Linguistics. I have benefitted from reading them all, including those which I do not explicitly mention.
} 
according to compositional semantics, the content of an expression should be a function of the contents of its parts. This suggests that the enclosed expression does not really count as a 'part' of the quotation built by enclosing it within quotation marks. What does that mean exactly? I will not be concerned with this issue here, but with a distinct issue involving open quotation and its content.

What is the content, or semantic contribution, of an open quotation? In contrast to closed quotation, an open quotation does not refer. A linguistic expression is ostensively displayed or, as I shall say from now on, 'demonstrated', without being linguistically referred to. So what is the content of, for example, the open quotation in (3) ? Well, it is unclear that an open quotation has content, or makes a semantic contribution, in the way in which closed quotations do. What is special about (3) - what makes it a case of quotation rather than a normal use of the words 'I am fed up with all this' - is arguably not a matter of semantic content. Whether I say 'I am fed up with all this' seriously, by way of making an assertion, or - as in (3) - echoically, to reproduce the previous speaker's utterance, is a matter of force rather than a matter of content. It has to do with what we do with words, rather than with what the words mean. Does it follow that open quotations have no meaning over and beyond the meanings of the demonstrated words ? Not quite. The speaker's act of ostensive display clearly means something. In (3) it means that the speaker is echoing the previous speaker's utterance. The speaker does so in order to convey something about that utterance, namely that it is not very constructive. But none of this is compositionally articulated in the way in which normal semantic content is compositionally articulated. What I have just described is, as I said, the meaning of the speaker's act of ostensive display. That meaning is pragmatic : it is the meaning of an act performed by the speaker, rather than the semantic content of an expression uttered by the speaker. Similarly, the speaker's act of raising his voice will, in appropriate circumstances, convey a certain meaning. This takes us to the heart of the difference between open quotation and closed quotation: while a closed quotation is elevated to the status of linguistic constituent and has a semantic content of its own, an open quotation is not and does not. In open quotation the speaker does something with the words, and thereby means something. What the speaker means by ostensively displaying the words should be clearly distinguished from what the words themselves mean. What the words mean is pretty determinate and can be computed by appealing to the semantic rules of the language. What the speaker means can only be inferred in context and lacks the determinacy of semantic content.

Example (3) is an instance of what Potts (2007) refers to as clausal (open) quotation. But the most interesting cases are the 'sub-clausal' instances, where the demonstrated words occur locally within sentences that are not, as a whole, demonstrated. (4), (5) and (7) below are examples of sub-clausal open quotation discussed in 'Open Quotation', while (6) comes from a book about Chateaubriand. I will concentrate on such cases from now on.

(4) John is very 'smart'.

(5) The demonstration provides the 'mode of presentation' of the referent, hence determines the contextual 'sense' of the demonstrative.

(6) Chateaubriand returned to France in 1800 , 'with the century'.

(7) A 'fortnight' is a period of fourteen days.

Given the local character of the quotation in such cases, we expect some interaction with the process of semantic composition which outputs the content of the global sentence in which 
the quotation occurs. Such interaction will be documented in sections 3-5, yet, I will argue, we need not significantly depart from the pragmatic view of open quotation sketched in the previous section.

In examples (4)-(7) the words within quotation marks contribute in the normal way to the semantic content of the sentence they occur in ; at the same time, however, they are demonstrated, and this contributes an extra level of meaning that is clearly pragmatic. The question that arises for the interpreter is : why is the speaker drawing attention to those words he is using ? If the speaker is reporting someone's speech, or has just done so, explicitly or even implicitly, then a likely explanation for the demonstration is that the speaker, by flagging those words, makes manifest that he is echoing the person in question - using his or her very words. ${ }^{2}$ In such cases I say that the 'point' of the quotation is ascriptional : the speaker wants to inform the hearer that the person in question used those words. Example (6) belongs to this category : by putting the words 'with the century' within quotation marks, the speaker implies that Chateaubriand himself, when describing the event of his return to France, used that phrase. In (5) the quoted words are famously associated with Frege, and the speaker, by flagging those words, presumably intends to make manifest that he is using Fregean terminology. Here the point is not ascriptional : the speaker does not intend to inform the hearer that Frege used the words 'mode of presentation' (that is common knowledge) : what the speaker intends to do, rather, is to warn the hearer that the terms ought to be taken in the technical sense they have in the Fregean literature, to evoke the proper background for the interpretation of the claims he is making by using them, and more generally perhaps to appeal to Fregean authority. In example (7), the reason why the speaker highlights the word 'fortnight' is that the sentence in which that word occurs may be taken as a definition of that word. Still, sentence (7) is not formally 'about words', but about things (namely, fortnights). There is a difference between that sentence, where the word 'fortnight' is used and the quotation open, and a metalinguistic sentence like (8), where the word is mentioned rather than used and the quotation belongs to the closed variety :

\section{'Fortnight' designates a period of fourteen days}

Finally there is the case of 'scare quotes', illustrated by (4) : the speaker indicates that the words she is using are not her words, that she is borrowing them from other people without fully endorsing them. Why is the speaker keeping those words at a distance is another question that has to be answered in order to fully grasp the meaning of the quotation. Another, related question that has to be answered bears on the nature of the attitude - playful, derisive, critical or whatever - which the speaker contextually expresses towards the source of the use she is echoing.

These are only a few typical examples. There is no limit to the number of more or less fine-grained explanations that can be found in context for the speaker's demonstration of some of the words he is using. Nor are the explanations in question exclusive of each other. Consider example (9), and what I said about it in 'Open Quotation' :

(9) Iouri Skouratov, general prosecutor, was suspended in March by Boris Eltsin. His successor, Iouri Tchaïka, was 'promoted' minister of Justice in August.

\footnotetext{
${ }^{2}$ I freely borrow some terminology (but not necessarily the associated doctrines) from other people. 'Flagging' comes from Predelli (2003, 2005b), 'echoing' from Sperber and Wilson (1981, 1986), and 'using other people's words' from Benbaji (2004).
} 
The quotation marks around 'promoted' convey many things to the interpreter: (i) that this term was officially used, or at least, that Iouri Tchaika's change of affectation was presented as a promotion, (ii) that the speaker (the newspaper columnist) does not fully endorse that description, (iii) that the reason why he does not is that it was not a real promotion, but rather a way of getting rid of Iouri Tchaïka by 'kicking him upstairs'... (Recanati 2001: 00)

The quotation here belongs both to the 'ascriptional' and to the 'scare-quotes' variety What, then, is the meaning of a sub-clausal open quotation? This question has no simple answer, and we need to draw a threefold distinction between

A- the meaning/content of the quoted words, i.e. their contribution to the meaning/content of the sentence they occur in ;

B- the conventional meaning of the quotation marks (or of their counterpart in oral speech);

$\mathrm{C}$ - the contextual meaning of the quotation.

- As far as A is concerned, not much needs apparently to be said : as I pointed out, in (4)-(7) the words keep their normal contents and make their normal contribution. Later, however, we shall see that in at least some cases of sub-clausal open quotation, the meaning/content of the quoted words is affected.

- As for B, there are two important issues to be addressed

- The first issue bears on the conventional meaning of the quotation marks. What is it exactly? So far I have suggested that the quotation marks merely flag the words as special and express the speaker's intention to draw the audience's attention to them. Alternatively, one may take the conventional meaning of the quotation marks to be more specific than that : maybe they indicate not only that there is something special about the enclosed words but also what is special about them, namely, that the speaker is using them echoically, so as to replicate the words used by some contextually identifiable source. This alternative is suggested by the fact that the quotations in (4)(6) are all clearly echoic, despite their differences. I will come back to that issue below. For the time being, in order not to pre-judge that issue, I assume that for some relation $R$ between the speaker and the words, the quotation marks indicate that the speaker is $R$-ing the enclosed words.

- Second issue : what is the status of that conventional meaning ? Does it, or does it not, belong to 'what is said', to the regular truth-conditional content of the utterance ? It seems that it does not. The speaker who utters any of (4)-(7) does not say that s/he $R \mathrm{~s}$ the enclosed words. That, rather, is a 'conventional implicature' (or, perhaps, a presupposition - see below). In my framework conventional implicatures are useconditional components of meaning (Recanati 1998 : §4). An expression conveys useconditional meaning if and only if it is governed by a condition of use in such a way that using the expression implies that the condition is satisfied. Now quotation marks have conditions of use : they are to be used only if the speaker is $R$-ing (or intends to be $R$-ing) the enclosed words. In virtue of this normative condition on the use of quotation marks, actually using them conventionally implicates that the speaker is $R$ ing the enclosed words.

- Finally, $\mathrm{C}$ is what we get when we answer the question : why is the speaker doing this $(R$-ing the enclosed words) ? Whatever reason can be contextually inferred for the speaker's quotational behaviour is part of the contextual meaning of the quotation. This is open-ended : there is no limit to the explanations one can give, in the sense that one can get as fine-grained 
as one wishes. In this respect the interpretation of an open quotation looks more like the interpretation of a literary text than like the computation of semantic content.

All this suggests a multi-dimensional analysis. $\mathrm{C}$ is a very different sort of beast than A. It's pragmatic, open-ended, and vague. It's a matter of all-things-considered inference, while semantic content can be computed on the basis of rules. Now B is a matter of rules, like $\mathrm{A}: \mathrm{B}$ is what the quotation marks indicate in virtue of the convention that governs their use. Yet $\mathrm{B}$ and $\mathrm{A}$ arguably remain separate. On the standard, multi-dimensional approach to conventional implicatures (originating in Frege) a given sentence may express several propositions, hierarchically ordered in terms of centrality for truth-evaluation. So a sentence compositionally expresses a given proposition, which is what has to be considered in evaluating the utterance as true or false. In addition, it may use-conditionally express further propositions whose bearing on the truth or falsity of the utterance is less obvious. Such a multiple-proposition framework has been put forward for dealing with, inter alia, conventional implicatures, and several authors, including myself, have suggested using it for dealing with (open) quotation. ${ }^{3}$ On the version of this view I put forward in 'Open Quotation', any of (4)-(7) compositionally expresses a certain proposition - the same it would express without the quotation marks - and use-conditionally expresses a further proposition to the effect that the speaker is $R$-ing the enclosed words. In addition the utterance pragmatically conveys an array of propositions having to do with the speaker's point in $R$-ing the enclosed words.

Bart Geurts and Emar Maier have objected to a multi-dimensional analysis, on the grounds that it is only 'suitable for representing different kinds of content that don't interact too much' (Geurts \& Maier 2005 : 113). There is a lot of interaction between the utterance's regular truth-conditional content and what the quotation contributes, they claim, so it is a mistake to posit 'a strict divide' between them (Geurts \& Maier $2005: 115$ ). Now, I agree that the meaning of an open quotation can affect the truth-conditions of the utterance in which it occurs; but I disagree that this necessarily goes against a multi-dimensional analysis. ${ }^{4}$ I also disagree with Potts, Cappelen \& Lepore and many other authors that such interaction goes against a pragmatic treatment like that which I advocate. Given the context-sensitivity of truth-conditional content, interaction with the pragmatic meaning of the quotation is predictable, since the action of quoting takes place in the very context with respect to which the sentence is assigned its truth-conditions.

There are two broad types of interaction between semantic content and quotational meaning in the sort of cases at issue. In this section I deal only with the first one, which involves the mechanism of 'free enrichment'. Through this mechanism, an expression is given a more specific interpretation, in context, than its semantic content strictly licenses (Recanati 2004).

\footnotetext{
${ }^{3}$ On the multiple-propositions framework, see Bach 1999, Neale 1999, Potts 2005, among others ; on its use in dealing with (open) quotation, see Recanati 2000, 2001, Predelli 2003, Garcia-Carpintero 2005, Potts 2007.

${ }^{4}$ Of course, it depends on what exactly one means by this. Geurts and Maier's main target is Potts (2007), and it is not my intention to defend Potts' account against their criticism. It may be that Geurts and Maier, whose view is similar to mine in many respects, would have no objection to the 'multi-level' analysis I defend in this paper. Yet they claim that their criticism applies to all versions of multi-dimensionalism, and they cite me as a would-be multidimensionalist.
} 
If, in describing a traffic-regulation scene, I say 'The policeman stopped the car', we naturally understand this as meaning that the policeman caused the car to stop by signalling to the driver that he was to stop, thereby leading him or her to do so. But the sentence itself says nothing about the means used by the policeman (it does not even say whether the stopping of the car was an intentional action on the part of the policeman). The italicized part in the above description corresponds to an aspect of the interpretation that is contributed by the hearer's expectations given his or her background knowledge. Since the speaker, who knows what those expectations are (and knows that the hearer knows that he knows), has done nothing to prevent the hearer from interpreting the utterance in this way, he clearly implies that this is the way the policeman stopped the car. Now this implicature is integrated with the semantic content of the utterance in such a way that they are not intuitively distinguished : the intuitive truth-conditions of the utterance incorporate the implicature.

Why is there pragmatic intrusion - i.e. incorporation of the implicature into 'what is said' - in this type of case but not in others $?^{5}$ Presumably, because the implicature further specifies the event which the sentence describes in virtue of its semantic content. The implicature provides an extra argument (the relevant 'way of stopping') in addition to the arguments that are linguistically articulated (the agent and the theme of the stopping event). Whenever an implicature overlaps with the semantic content of the utterance in this way by providing further specifications of the described event, it tends to get incorporated into the utterance's intuitive truth-conditions, instead of remaining intuitively separate as when its contribution is orthogonal to semantic content.

In some cases, similarly, the meaning of an open quotation can easily be integrated with the semantic content of the utterance, because they overlap. Consider (6). The quotation is echoic, I said, and its point is ascriptional : it contextually means that Chateaubriand, in describing the event of his return to France, used those very words ('with the century'). This (Chateaubriand's using the words 'with the century') is a distinct event from that which the main proposition describes (Chateaubriand's returning to France in 1800, with the century), so the 'overlap' condition is not satisfied. But let's change the example a bit :

(10) In Mémoires d'outre-tombe, Chateaubriand wrote that he returned to France in 1800 , 'with the century'.

Here the main proposition describes the event of Chateaubriand's saying something about his return to France. The meaning of the quotation - which arguably does not change - can easily be integrated with that proposition since it is about the same event, which it further specifies by providing an additional argument to the 'saying' relation (viz. the words that Chateaubriand used in saying what he said). As a result of this integration, an ordinary user of the language asked about the truth-conditions of $(10)$ is likely to respond that the utterance is true if and only if, in Mémoires d'outre-tombe, (i) Chateaubriand wrote that he returned to France in 1800, and (ii) he used the word 'with the century' to describe the timing of his return.

The quotation, in example (10), clearly contributes to the truth-conditions of the utterance. Does it follow that quotational meaning and semantic content do not belong to separate dimensions ? I do not think so. I think we can maintain that the contextual meaning of the quotation (to the effect that Chateaubriand used those very words) belongs to a different dimension than the semantic content of the utterance, if we accept that an utterance's intuitive truth-conditions can go beyond what semantic content provides. As the policeman example has shown, the literal truth-conditions of an utterance can be pragmatically enriched

\footnotetext{
5 The phrase 'pragmatic intrusion' comes from Levinson (2000).
} 
with further specifications of the described event which the context, or general worldknowledge, makes available even though they are not linguistically encoded. Another wellknown example of that sort of thing which I mention in 'Open Quotation' (and elsewhere) is:

She took out her key and opened the door

It is natural to interpret the second conjunct as meaning that the person referred to by 'she' opened the door with the key mentioned in the first conjunct; yet the sentence does not literally say anything about the instrument used in opening the door. The further specification of the opening event through the contextual provision of that instrument results from free enrichment. This is like an ordinary conversational implicature, but in that sort of case the implicature overlaps with the main proposition expressed by the second conjunct (that she opened the door) since it further specifies the event of opening the door by providing an additional argument (the key mentioned in the first conjunct). The implicature therefore tends to intrude into the utterance's intuitive truth-conditional content : the latter is pragmatically enriched through incorporation of the implicated component.

Something similar arguably happens in (10). The intuitive truth-conditional content of the utterance is enriched through the incorporation of the meaning of the quotation. But this possibility does not argue against a multi-dimensional treatment. The fact that the meaning of the quotation can be incorporated into truth-conditional content through free enrichment does not show that it is not 'separate' from semantic content. If it did, then the fact that a piece of contextual information or world-knowledge, or a conversational implicature, can be integrated into the intuitive truth-conditional content of an utterance through free enrichment would similarly show that that piece of information is not separate from semantic content - an absurd conclusion. One may deny that free enrichment exists, but if it exists, then it provides an explanation of the interaction of semantic content and quotational meaning in (10) that is fully compatible both with multi-dimensionalism and with a pragmatic approach to open quotation.

The second form of interaction between quotational meaning and semantic content I mention in 'Open Quotation' involves the phenomenon of context-shift. We have seen that in many cases, open quotation is echoic : the speaker's use of the demonstrated words is meant to echo the words used by someone else. Let us draw a distinction between the current context - the context in which the quotational demonstration occurs - and the source context (the context of the original use which the quotation is meant to echo). Though the same words are used in the current context as in the source context, they may carry different contents with respect to the two contexts. There will be such a potential divergence in content whenever the words in question include an indexical expression which takes different values in the two contexts, or whenever the words at issue happen not mean the same thing in the two contexts. (Think of the case in which a British speaker echoes an American's use of an English word which means different things in British English and American English.) Now, if the speaker is recognized as intentionally echoing the source's use of the same words, it will be natural, in such cases, to construe the speaker as deliberately using the demonstrated words with the meaning/content they had in the source context, rather than with the meaning/content they would carry had they been used 'plainly' (non-echoically) in the current context.

An example from 'Open Quotation' is

Paul says he's due to present his work in the 'paper session' 
where the speaker is understood as mimicking Paul's deviant use of the phrase 'paper session'. What Paul meant when he said what (12) reports was that he was due to present his work in the poster session. Ironically echoing Paul's mistaken use, the speaker ascribes to him reference to the poster session under the wrong name. Here what the words 'paper session' contribute to semantic content is not their regular semantic value, but rather the semantic value they have in Paul's idiolect (given that he uses 'paper' to mean 'poster'). In such cases semantic content is affected by the quotational demonstration. Similarly, when the quoted words include an indexical expression, that expression may have to be interpreted with respect to the source context rather than the current context, as in this example from the New York Times cited in 'Open Quotation' :

(13) Levi Foster, in fact, is the great-great-grandfather of Gov. Mike Foster of Louisiana, who said recently on a radio program that it would be 'news to me' if anyone in his family had owned slaves.

The first-person accusative 'me' within the quoted material refers to the speaker in the source context, namely Mike Foster, rather than to speaker in the current context, namely the utterer of (13). ${ }^{6}$

In the standard, Kaplanian sense of 'context', only (13) involves a context-shift. Example (12) involves what I dubbed a language-shift : the words within the quotation marks are interpreted as belonging to the 'language' (idiolect) of the source, and this affects not only their content but also their linguistic meaning or character. Yet, as I pointed out in several places, the two phenomena can be unified if we let the language spoken in a context be one of the coordinates of the context in question. ${ }^{7}$ In this framework, which I adopt in what follows, both (12) and (13) involve a context-shift.

In (12) and (13) the semantic content of the sentence is not the same as what we get when we remove the quotation marks. So it seems that the quotation contributes to semantic content in such cases. Yet a distinction can be drawn between straightforwardly contributing to semantic content, and merely having an effect on semantic content. Open quotation has an obvious effect on semantic content in cases like (12) and (13), but that effect can be decribed as pre-semantic. It need not be taken as a genuine 'contribution to' semantic content.

Let us assume, with David Kaplan, that semantics maps sentence-context pairs to contents (intensions). Both 'sentences' and 'contexts' are theoretical constructs intended to track relevant properties of utterances and the situations they are produced in. As Predelli (2005a) forcefully pointed out, before semantics can apply to deliver the content of a particular utterance, a representational problem arises : one must decide which (abstract) 'sentence' will adequately represent the concrete utterance that was made, and which (abstract) 'context' is relevant to the interpretation of that sentence. These representational problems are not trivial. Most linguistic signals are ambiguous and a decision has to be made, on pragmatic grounds, to decide which sentence is actually uttered among several competitors comptatible with the perceptible signal. (As Bar-Hillel emphasized, in all cases a

\footnotetext{
${ }^{6}$ The same shift from current context to source context in interpreting an indexical within an echoic quotation can be observed with both clausal open quotation and closed quotation. In examples (2) and (3), arguably, the quoted sentence 'I am fed up with all this' is to be construed as echoing the source's use of the same words, and as retaining the content it had when it was uttered by the source.

${ }^{7}$ Another coordinate we need is the world of the context. See footnote 17 for a case in which a context-shift affects the world coordinate of the context.
} 
pragmatic decision has to be made to determine the language to which the uttered expression belongs. $)^{8}$ Sometimes, Predelli (2005b) suggests, it may even be advisable to assign the perceptible signal to a sentence that is not formally compatible with it, if the speaker's performance happens to be faulty but his or her linguistic intention is sufficiently manifest to determine which expression $\mathrm{s} /$ he intended (but failed) to token. ${ }^{9}$ Be that as it may, the representational problem has to be solved before semantics can apply to a given utterance. Similarly, before semantics can apply, one has to decide which context the sentence counts as uttered in. This may sound trivial but it is not : the relevant context need not be the situation in which the utterance is actually made. In Oratio Obliqua, Oratio Recta (Recanati 2000 : 271) I gave the following example :

(14) It's been three years since we left the Earth. A couple of weeks after the Last Day, we lost track of the other spaceships. I still don't know what happened to my twin brother Henry. If he is alive, he probably thinks I died in the collision.

Let's imagine that this is the first paragraph of a novel. What is the context for those sentences? A first candidate is the actual situation of utterance: the novelist writes those sentences at the beginning of her novel. Yet the word ' $I$ ', in the third sentence, does not denote the novelist; rather, it purports to denote a character in the novel - the so-called 'narrator'. The novelist pretends that (14) is uttered by that character, and it is that pretend context, rather than the actual context, which is relevant for interpreting the sentences in (14). In the pretend context, the speaker (i.e. the narrator, distinct from the novelist) is on board of a spaceship, he or she has a twin brother called 'Henry', there has been a collision, etc. The representational problem here consists in selecting the right context (viz. the pretend context) as the proper context for the interpretation of the sentences in (14). This is not something that semantics can do, anymore than disambiguation is something semantics can do. Both disambiguation and context-selection are complex pragmatic tasks involving massive amounts of world-knowledge (knowledge of what a novel is, etc.) and a proper appreciation of the speaker's intentions.

Let us take stock. To get a semantic content in the first place, we need a meaningful expression $e$ in some language $L$ and a context $c$ to fix the values of the indexicals in $e$. The semantic rules of $L$ are supposed to determine the content of $e$ with respect to $c$. So $e$ and $c$ are the inputs to the semantic machinery, and semantic content is the output. The representational problem Predelli talks about consists in selecting the proper inputs. That is where open quotation, in examples like (12) and (13), arguably comes into the picture. In (13) the speaker's echoic demonstration suggests that the relevant context for evaluating the enclosed words is the source context rather than the current context. In (12) it suggests that the relevant expression $e$ is not the word 'paper' of the language of the current context, but the word 'paper' in Paul's idiolect (a faulty approximation to the word 'poster' in the language of the current context). If this is right, then the effect of quotation on semantic content is, indeed, pre-semantic : quotation affects semantic content indirectly, by affecting the inputs that are

\footnotetext{
8 'Any token has to be understood to belong to a certain language. When somebody hears somebody else utter a sound which sounds to him like the English 'nine', he might sometimes have good reasons to believe that this sound does not refer to the number nine, and this in the case that he will have good reasons to assume that this sound belongs to the German language, in which case it refers to the same as the English 'no'. In this sense, no linguistic expression is completely independent of the pragmatic context' (Bar-Hillel 1954, p. 80).

${ }^{9}$ Thus when George Bush, whose command of English is less than perfect, uses the non-word 'subliminable', it is clear that he intends to be using the English word 'subliminal'.
} 
fed to the semantic machinery. Similarly, the speaker's German accent or the fact that we are in Germany may suggest that the word that has just been uttered is the German word 'nein' rather than the English word 'nine'. Such a suggestion has an obvious effect on the semantic content that is ascribed to the utterance, yet that effect is entirely pre-semantic

It may be objected that the effect of at least sub-clausal open quotation has got to be construed as semantic (rather than merely pre-semantic), for the following reason. In the kaplanian framework I have just appealed to, semantics maps sentence-context pairs to contents by assigning characters (functions from contexts to contents) to sentences. Now, how do we assign a character to a sentence like (12) or (13) ? Whichever context we interpret the sentence in, we won't get the right content, since (because of the sub-clausal context shift) we need two contexts rather than one. To interpret (12) or (13), we need both the current context and the source context. So the representational problem (which context are we to interpret the sentence in) cannot be solved for the global sentence. We may, of course, revise the framework and decide e.g. that only simple expressions will be assigned characters : for more complex expressions like sentences, we will directly compose the contents determined by the characters of the parts in their respective contexts, instead of first composing the characters of the sentential parts to get the character of the sentence, and then determining the content of the sentence by applying that character to 'the' context of the sentence. (See King and Stanley 2003 for the suggestion that we don't need characters for global sentences.) But suppose we want to stick to the unrevised kaplanian framework: what can we do ? Well, the obvious solution consists in semanticizing the context-shift and making it, as it were, internal to the character of the global sentence. This we can do by assigning to the sub-clausal quotation a metalinguistic character, which maps the context in which the sub-clausal quotation occurs (viz. the current context) to the content expressed by the enclosed expression when interpreted in the source context. On this view the quotation marks function as a context-shifting operator $d$. That operator combines with an expression $\sigma$ (the expression within the quotation marks) to yield an expression of the same type, and shifts the context for the interpretation of $\sigma$ from the current context $c$ to the source context $c$ '. So, in the current context, the character of $d \sigma$ determines the same content as the character of $\sigma$ in the source context. Through this semanticization of the context-shift, which is now built into the metalinguistic character of the quotation, we can interpret the global sentence with respect to a single context (the current context) and get the right results : for the expression $d \sigma$ which occurs in the sentence is such that its own interpretation in the current context proceeds via the interpretation of $\sigma$ in the source context.

I have no objection to such an analysis, which I myself put forward in Oratio Obliqua, Oratio Recta (Recanati 2000 : chapter 17) ${ }^{10}$ But I want to qualify the conclusion that the contribution of the quotation is thereby 'semanticized'. In one sense it is - the context-shift is, indeed, built into the character of the sub-clausal quotation - but in another sense it need not be. We can accept that the sub-clausal quotation has a metalinguistic character and can be formally represented as $d \sigma$, where $d$ is a context-shifting operator. But we need not consider the quotation marks in the object-language as themselves such an operator. Rather, we can maintain what I said earlier about them : that their only semantic contribution is a conventional implicature, to the effect that the speaker is $R$-ing the enclosed words. In the relevant contexts, the speaker's $R$-ing the enclosed words suggests that a context-shift occurs

${ }^{10}$ The context-shifting analysis has its roots in Recanati 1997 (where I use the 'deferential operator') ; see also Benbaji 2004 for an analogous proposal. 
at the boundary marked by the quotes ; and such an intra-clausal context-shift has a semantic effect that is best captured (within the standard kaplanian framework) by positing a contextshifting operator in the abstract formula which represents the utterance and serves as one of the inputs to the semantic machinery. On this view, the context-shifting operator need not have any syntactic realization in the object-language : the theorist uses it to perspicuously represent the context-shifting effect of the quotational demonstration. The suggestion is that, whenever an intra-sentential context shift occurs, whether or not it is conventionally signalled by a specialized linguistic device, a context-shifting operator has to be posited that 'represents' this context-shift and makes it visible to the semantics. ${ }^{11}$ This leaves two options open with respect to the quotation marks : either we treat them as the object-language realization of the context-shifting operator and give them the corresponding semantics, or we simply consider that they signal the fact that the speaker is $R$-ing the enclosed words, which fact in turns suggests that a context-shift occurs and makes insertion of a covert operator $d$ appropriate in the formal representation of the utterance. In Oratio Obliqua, Oratio Recta I took the latter position (Recanati $2000: 253$ ), but I admit this is a controversial issue.

Should the quotation marks be construed as a context-shifting operator, or do they merely convey a conventional implicature (to the effect that the speaker is $R$-ing the enclosed words) which pre-semantically affects the character of the utterance by suggesting a context-shift? ${ }^{12}$ This question is directly related to the issue raised in section $2:$ what is the conventional meaning of the quotation marks?

The quotation marks, I said, signal that the speaker is $R$-ing the enclosed words. What is the relation $R$ ? I mentioned two options : either the speaker merely calls attention to the enclosed words, demonstrates them, suggesting that they are used in a special manner; or, more specifically, the quotation marks signal that the speaker uses the enclosed words echoically. If we take the first option, the echoic interpretation is only one contextual interpretation of the speaker's act of drawing attention to the enclosed words, among other possible interpretations. On the second option, the echoic interpretation is what the quotation marks themselves encode : putting words within quotation marks means that one is using them echoically, i.e., that one is thereby evoking some use of those same words in a source context $c^{\prime}$ distinct from the current context. I am going to argue that, if we choose this option, it will be very hard to resist the claim that the quotation marks are an object-language realization of the context-shifting operator.

I mentioned two cases of context shift in sub-clausal open quotation : the case in which the quoted words include an indexical expression whose semantic value varies across contexts, and the case in which the quoted words include an expression whose linguistic meaning varies across contexts. In both cases, the content of the enclosed words changes as a result of the shift. Now, most echoic uses are such that the content of the quoted words remains unaffected. Consider examples (4)-(6) once again :

\footnotetext{
${ }^{11}$ In many cases we need to posit the context-shifting operator in order to get a coherent interpretation, even if the context-shift is not explicitly signalled by quotation marks or anything else.

12 That the character of an utterance may be affected by pragmatic facts, rather than being entirely and exclusively determined by the conventions of the language in a contextindependent manner, is something we know already from the study of demonstratives. (A sentence in which a demonstrative occurs has a determinate character only if the demonstrative is completed, in context, by an appropriate 'demonstration'.)
} 
(4) John is very 'smart'

(5) The demonstration provides the 'mode of presentation' of the referent, hence determines the contextual 'sense' of the demonstrative.

(6) Chateaubriand returned to France in 1800 , 'with the century'.

These quotations are echoic (the speaker tacitly refers to some use of the quoted word in a source context distinct from the current context), yet the content of the sentence is the same as it would be if we removed the quotation marks. This might be taken to show that not all echoic uses involve a context-shift. On this view, we can resist the claim that the quotation marks are an object-language realization of the context-shifting operator, even if we take them to encode the fact that the speaker is using the enclosed words echoically.

But the reasoning that leads to that conclusion is faulty. A context-shift may occur without affecting the content of the words it concerns, so the fact that certain echoic uses do not affect the content of the quoted words does not show that no context-shift occurs. In Oratio Obliqua, Oratio Recta I defined a context-shift as 'conservative' whenever the content of the words at issue is the same in the current context and the source context. In such cases the context-shift has no effect on content. That is, arguably, what happens in (4)-(6) : in virtue of the context-shift, the word 'smart' within quotation marks denotes the property which the word 'smart' denotes in the source context. Since the word 'smart' denotes the same thing in the source context and the current context, the word 'smart' within quotation marks denotes the same thing as the word 'smart' without the quotation marks (i.e. without the shift). The context-shift is therefore conservative : it does not affect the content of the sentence ; but it affects its character, since the character of the expression within quotation marks is now metalinguistic. Again, 'smart' within quotation marks denotes what 'smart' denotes in the source context. (This formula 'says' what the content of the expression in quotes is and at the same time 'shows' its metalinguistic character. ${ }^{13}$ )

Since context-shifts can be conservative, there is no reason to deny that, by using words echoically, one shifts the context for their interpretation from the current context to the source context. This may, or may not, entail a change in content for the enclosed words, but in all cases a change in character results. So, to say that the quotation marks conventionally mean that one is using the enclosed words echoically is to say that they are an object-language realization of the context-shifting operator $d$. On this view, the quotation marks affect the character of the words they attach to, making it metalinguistic : the character of an expression within quotation marks maps the current context (the context in which the quotation occurs) to the content expressed by the enclosed expression when interpreted in the source context. That metalinguistic character is defined only for contexts in which the speaker (i.e. the person who quotes) tacitly refers to some use of the quoted expression in a source context $c$ ' distinct from the current context. So the conventional implicature, to the effect that the speaker is echoing some use of $e$ distinct from the current use, can be redescribed as a presupposition of the quotation. In contexts in which the presupposition is not satisfied (i.e. no use of $e$ is echoed by the speaker) the metalinguistic character returns no content.

We still have to choose between the first and the second option as far as the conventional significance of quotation marks is concerned. Do the quotation marks mean that the enclosed words are used echoically (in which case they are best analysed as a contextshifting operator), or do they have a vaguer and more general meaning, that of mere 'danger

\footnotetext{
${ }^{13}$ What is being echoed by the sub-clausal open quotations in this sentence is Dummett's use of the Wittgensteinian show/say distinction to explain the idea that a theory of reference can 'serve as' a theory of sense.
} 
signal'? To answer this question we must determine whether all uses of quotation marks are echoic, or whether the echoic interpretation is only one contextual interpretation among others.

It is pretty clear that not all uses of quotation marks are echoic. Many instances of closed quotation are not: the speaker talks about words without evoking any use of those words in a source context distinct from the current context. Example (1) belongs to this category of 'flat mention'. One of the merits of the idea that quotation marks are a danger signal by means of which the speaker draws attention to the words he is using and 'demonstrates' them is precisely the fact that it applies to both open and closed quotation (what distinguishes closed quotation being an additional feature). In contrast, the alleged context-shifting function of quotation marks cannot be generalized to all cases of quotation. But this is not a decisive objection to the echoic view, for the semantic properties of closed quotation are, in any case, special, and it is by no means clear that we need a unified semantics for open and closed quotation, at whatever level. So closed quotation is not directly relevant. Nor is clausal open quotation directly relevant. What we are concerned with is subclausal open quotation, for that is the type of case that casts doubt on the claim that open quotation (whether clausal or sub-clausal) is a pragmatic phenomenon that calls for a multidimensional analysis. Indeed, if the quotation marks in sub-clausal open quotation can uniformly be analysed as the context-shifting operator $d$, this would argue in favour of the type of semantic analysis which Geurts and Maier provide : a semantic, one-dimensional analysis. So the question we must answer is : Are all instances of sub-clausal open quotation echoic ? Or are there cases of flat mention among them ? $^{14}$

In previous work I argued that there are non-echoic instances of sub-clausal open quotation, and I provided (7), repeated below, as an example :

A 'fortnight' is a period of fourteen days.

The speaker of ( 7 ) does not tacitly evoke some use of 'fortnight' in a source context distinct from the current context, I claimed. He or she means to convey something about the word 'fortnight', without echoing any particular use of it. This is a case of 'flat mention' very much like (1), save for the fact that the quotation is open rather than closed.

But I am no longer so sure. Maybe the speaker of (7) is tacitly referring in some generic manner to the use of 'fortnight' by whoever, in the linguistic community, correctly uses that word. Maybe the character of 'fortnight' in (7) is made metalinguistic by the quotation marks and can be spelled out as thing called 'fortnight' or something like that. If this type of example is our only reason for resisting the echoic analysis, that is clearly not sufficient. What is required, at this stage, is a detailed empirical investigation of the phenomenon of sub-clausal open quotation, in order to answer the question : are there unmistakable instances of flat mention among them, or more generally cases that cannot be given an echoic interpretation ? For the time being, I want to remain agnostic and will leave that issue open.

Where does this leave us with respect to Geurts and Maier's criticism of the multidimensional analysis ? Let us look at their own analysis. In the relevant type of case, they claim, the quotation marks around an expression $e$ presuppose that there is a speaker $x$, a useevent $u$ distinct from the current use, and an entity $Z$ (of the same type as the regular

\footnotetext{
${ }^{14}$ Gomez-Torrente claims that there are also non-echoic uses that are not instances of flat mention. He mentions certain 'scare-quoting' uses that he thinks are not echoic (2005: 150, fn 22); but I am not convinced by his example, which seems amenable to a context-shifting analysis.
} 
denotation of $e$ ) such that $u$ involves $x$ 's expressing $Z$ by means of $e$. Besides this presupposition, which is to be resolved by either 'binding' $x, u$ and $Z$ to suitable antecedents provided by the context or by 'accommodating' them, the regular semantic content of the quotation just is the entity $Z$, which it denotes. The upshot is that, in the current context, the quotation denotes whatever the quoted expression denotes in the source context. This is equivalent to the 'metalinguistic character' analysis in terms of the context-shifting operator $d$. Note that the metalinguistic character theory also appeals to presupposition (see above). But the binding theory of presupposition in which Geurts and Maier couch their proposal enables them to make clear what distinguishes their account from two-dimensional approaches : since they treat presuppositions as a form of anaphora that has to be 'resolved' in the course of semantic interpretation (rather than as a separate component that is 'passed along' as we move upwards the semantic tree, as in Potts's multi-dimensional analysis), they are able to provide a one-dimensional treatment that integrates the conventional contribution of quotation marks with regular semantic content.

Should it turn out that sub-clausal open quotation is always echoic, I would have no objection to this analysis. Again, it is equivalent to the metalinguistic character approach of Oratio Obliqua, Oratio Recta. But that does not mean that I give up two-dimensionalism in the analysis of open quotation. I think we still need two dimensions, even if we accept the Geurts-Maier analysis : for we still haven't captured the contextual meaning of the quotation, which has to do with the reason why the speaker is echoing the source's use of the same words. In some cases, the speaker's aim is to inform the hearer that the source used the quoted words ; in other cases she wants to distance herself from those words or to indicate that she does not fully endorse them, because they are inadequate or for whatever reason the context may make manifest ; in still other cases she wants to appeal to authority by using words recognizably associated with the source; and so on and so forth. If we leave aside what I called 'the contextual meaning of the quotation', we get only a truncated account.

I conclude that, even if we take echoicity to be the conventional significance of subclausal open quotation, we still need a complex picture with several levels, in the spirit of what I proposed. We still need to distinguish between issues $\mathrm{A}, \mathrm{B}$, and $\mathrm{C}$. The answers we get if we take this option are the following :

- $\quad$ [B : Conventional meaning of the quotation marks] The quotation marks signal that the speaker is using the enclosed words echoically and tacitly refers to some use of the same words in a source context $c$ ' (to be contextually identified).

- [A : meaning/content of the quoted words] Semantically, this has the effect of shifting the context for the interpretation of the enclosed words, making their character metalinguistic. This may, or may not, affect the content of the words in question.

- $\quad[\mathrm{C}$ : Contextual meaning of the quotation $]$ Pragmatically, this raises the issue of 'quotational point' - the speaker's reason for echoing. The answer to that question provides the contextual meaning of the quotation, which remains separate (though it may get into the truth-conditions via free enrichment, as indicated in section 3 ).

The gist of the pragmatic approach I advocate is that quotation involves the speaker's doing something (' $R$-ing' the quoted words, whatever that turns out to be) and thereby implying a number of things having to do with the reasons why s/he does so. The contextual meaning of the quotation is something we get to through interpreting the speaker's action, not something that results from mechanically applying a set of rules. Whether or not, semantically, the quotation marks function as a context-shifting operator does not change that basic position. It 
may be that the quotation marks systematically affect the meaning of the sentence they occur in, without the contextual meaning of the quotation itself resulting from such the application of semantic rules.

Nor is the pragmatic approach undermined by the fact that the contextual meaning of the quotation makes a difference to the utterance's truth-conditions. That it does is shown by the phenomenon known as 'mixed quotation'. Mixed quotation is the case, illustrated by (10) and (12), where an utterance which reports a locutionary act performed by some agent $x$ specifies the content of that act by using a 'that'-clause as complement of the locutionary verb $V$, and at the same time specifies (some of) the words actually used by the agent through a sub-clausal quotation inside the 'that'-clause :

(10) In Mémoires d'outre-tombe, Chateaubriand wrote that he returned to France in 1800, 'with the century'.

(12) Paul says he's due to present his work in the 'paper session'

An utterance like (10) intuitively entails that Chateaubriand used the words 'with the century' in performing the locutionary act that is being reported. In general, a mixed-quotational utterance ' $x V$-ed that ...' '...' entails that the agent $x$ used the quoted words in performing the locutionary act $V$ that is being reported. Now I take the 'entailment' in question to result from free enrichment through incorporation of the contextual meaning of the quotation. More precisely, it is generated through the following mechanism. (1) By ostensively quoting the words in the context of reporting Chateaubriand's description of his return to France, the speaker manifests his intention to inform the hearer that Chateaubriand used those very words. That is the 'contextual meaning' of the quotation. (2) By thus making his informative intention mutually manifest, the speaker communicates that piece of information to the hearer (in the Gricean sense of communication as 'non-natural meaning'). (3) The piece of information thus pragmatically imparted overlaps with the utterance's semantic content and fuses with it through the mechanism of free enrichment. ${ }^{15}$

Many authors reject the free enrichment account, because they think whatever is clearly part of truth-conditions must be accounted for in terms of semantic rules. Of course, this cannot be the argument invoked for rejecting the account, since that would beg the question. So what is the argument ? Well, the only argument I have been exposed to is the following. The relevant 'entailment' (to the effect that Chateaubriand used those words) cannot simply be a pragmatic suggestion that has found its way into semantic content, for if it were, it should be cancelable — but it is not! This is the Gricean test for telling apart the semantic from the pragmatic : pragmatic suggestions, by their very nature, can be cancelled, either contextually or explicitly. I agree that it is this sort of consideration that should be appealed to for settling the issue, though, of course, I disagree that in the present case, the test argues against the free enrichment account.

Cappelen \& Lepore have explicitly appealed to cancelability in arguing against the pragmatic approach to mixed quotation (Cappelen \& Lepore 2005, 2007). Their argument proceeds in two steps :

1. If a component of content expressed by a sentence $S$ is not cancelable, then we have good reason to think that this feature is part of the semantic content of $\mathrm{S}$.

${ }^{15}$ The same mechanism is arguably responsible for the 'clearly contrastive entailments' which Potts (2007) detects in the following sentences :

(16a) When in Santa Cruz, Peter orders '[eI]pricots' at the local market

(16b) When in Amherst, Peter orders '[æ]pricots' at the local market. 
2. In an instance of mixed quotation like (10), or Cappelen and Lepore's own example (17), the ascription of the quoted words to the agent whose locutionary act is being reported (Chateaubriand in (10), Alice in (17)) cannot be canceled.

Alice said that Bill Clinton is 'smooth'

Just as (10) entails that Chateaubriand used the words 'with the century' in performing the locutionary act which (10) reports, (17) entails that Alice used the exact word 'smooth' when she described Clinton as smooth. These entailments are not cancelable, Cappelen and Lepore say. That they are not 'is evidenced by the fact that there are no true utterances of (18')' (Cappelen \& Lepore 2005 : 66) :

(18) Alice said that Bill Clinton is 'smooth', but she never used 'smooth'.

Now I accept the first premiss in Cappelen \& Lepore's argument, but I reject the second premiss. Indeed, both in Oratio Obliqua, Oratio Recta and in 'Open Quotation', I pointed out that the ascription of the quoted words to the agent of the locutionary act being reported is cancelable.

A mixed quotation is a sentence of the schematic form ' $x V$ that $p$ ' where the 'that'clause contains a sub-clausal open quotation. Let us grant that sub-clausal open quotations are (typically) understood as echoic : the speaker tacitly refers to some use of the quoted words by some agent $y$ in the course of a speech event $e$. To get the entailment that $x$ used the quoted words in performing the act $V$ which the sentence reports, it is necessary that the reportee $x$ and the echoee $y$ be one and the same person. Further, it is necessary that the locutionary act $V$ and the speech event $e$ be identified. ${ }^{16}$ Even when those conditions are met, we get the relevant entailment only if the speaker's 'quotational point' is ascriptional. If it is not, we don't get the entailment. So there are three ways to contextually 'cancel' the implication that $x$ used the quoted words in performing act $V$. We may contextually equate the echoee with some person $y \neq x$; or we may equate $x$ and $y$ but take $V$ to be performed in a speech event $e$, distinct from the speech event $e$ being echoed; or the point of the quotation may not be ascriptional (for example, the speaker may simply wish to distance himself from $x$ 's use of that word). In all such cases it will not be part of the truth-conditions of the utterance that $x$ used the quoted words in performing act $V$.

Take Cappelen \& Lepore's example (17). To get rid of the entailment that Alice used the exact word 'smooth' when she described Clinton as smooth, we only have to imagine a context in which, by using 'smooth' echoically, the speaker tacitly refers to some use of the word 'smooth' by some agent $y$ distinct from Alice. That person $y$ might be the hearer, as in this variant :

(19) Alice said that Clinton is 'smooth', as you would put it. Of course that's not the word she used.

The 'as you would put it' is optional : it may be contextually clear that the speaker is echoing the hearer's use of 'smooth' rather than Alice's. (We have to imagine a scenario in which that word is saliently associated with the hearer, perhaps because he keeps using it, while it is

\footnotetext{
${ }^{16}$ In earlier work I used the notion of 'target' to refer to the use being echoed. The target, so understood, involves both a particular agent and a particular speech event. However it is better to clearly distinguish between the agent and the event, as Geurts and Maier do in their otherwise similar account.
} 
known that the word does not belong to Alice's vocabulary.) So I think it is quite possible, in the right context, to imagine someone sensibly uttering Cappelen \& Lepore's 'impossible' sentence $(18){ }^{17}$

In Oratio Obliqua, Oratio Recta I gave an example in which a third party's use of the quoted word is being echoed :

Paul says that 'Quine' is late for his own paper

What is being ironically echoed here is (not Paul's but) James' mistaken use of the name 'Quine' to refer to McPherson : the speaker of (20) mockingly uses that name to refer to McPherson in reporting Paul's statement that he (McPherson) is late for his own paper. The use of the name 'Quine' is not ascribed to the person (Paul) whose locutionary act is being reported. The person whose use of the name 'Quine' is being echoed is a third party (James) who mistakes McPherson for Quine.

The fact that the use of the name 'Quine' which is being echoed in (20) is a mistaken and deviant use - like the use of 'paper' in (12) — is an irrelevant feature of this particular example, which was originally introduced in connection with the phenomenon of (intraclausal) language-shift. It is easy to get rid of that feature while retaining the structure of the example. Let us imagine that the person who is said to be late for his own paper is Quine himself, and that the speaker utters (21):

\section{Paul says that 'Mr Quine' is late for his own paper' ${ }^{18}$}

Again, it may be that the use of the words 'Mr Quine' which is being echoed in (21) is their use by a third party, James, who always refers to Quine as 'Mr Quine'. Paul is not aware of that fact, and he simply refers to Quine as 'Quine'. But when reporting his locutionary act, the speaker ironically uses James' phrase. This is a de re report : there is no intention on the speaker's part to ascribe the use of the phrase 'Mr Quine' to Paul, whose speech act he is reporting. The speaker freely chooses that phrase to report Paul's statement (that's what makes the report de re), and the use of that phrase in the speaker's mouth is clearly echoic : it ironically echoes James' use of it. In this context, the suggestion that Paul (the agent of the reported locutionary act) used the quoted phrase in performing the locutionary act that is being reported is clearly absent. This shows that the suggestion in question is contextually cancelable. According to Grice's characterization, an implicature 'is contextually cancelable if one can find situations in which the utterance of the form of words would simply not carry the implicature' (Grice $1989: 44$ ). In the case of mixed quotation, the relevant 'form of words' is a sentence ' $x V$ that $p$ ' where the 'that'-clause contains an open quotation. As (19)(21) show, nothing is easier than to find situations in which such a form of words does not carry the implication that the agent $x$ used the quoted words in performing the act $V$ which is being reported.

It is surprising that Cappelen \& Lepore use the cancelability argument against the pragmatic account ; for in both Oratio Obliqua, Oratio Recta and 'Open Quotation', I pointed out that the relevant implication is cancelable. I did so in footnotes, however, and those footnotes apparently escaped Cappelen \& Lepore's attention on their first reading. When they took notice, they came up with a response (Cappelen \& Lepore 2005 : 67-69) which has also

\footnotetext{
${ }^{17}$ Here the quotation marks around 'impossible' are to be interpreted by shifting the world coordinate of the context.

${ }^{18}$ This is reminiscent of the 'M. Auguste' example which I discussed at length in my first piece of work on sub-clausal open quotation (Recanati 1979 : chapter 4).
} 
tempted other commentators (Gomez-Torrente $2005: 134-135)$ and which I am now going to discuss. The methodological issues they raise concerning the semantics/pragmatics boundary provide an appropriate topic for the concluding section of this paper.

Cappelen \& Lepore and Gomez-Torrente argue that we shouldn't speak of 'cancelability' if the form of words at issue is, or can be taken to be, ambiguous. Consider an ambiguous form of words $F$, e.g. the sentence 'I am going to take a bath close to the bank' (Gomez-Torrente's example), uttered in a context $c$ that makes a certain reading $R$ salient (e.g. the reading on which 'bank' is taken in the sense of RIVER BANK). Since $F$ is ambiguous, it will be possible to find a situation (a context) $c$ ' such that, were $F$ tokened in $c$ ', an alternative reading $R$ ' (e.g. the reading on which 'bank' is taken in the financial sense) would be more salient than $R$. Does this amount to contextually 'canceling' whatever implications distinguish $R$ from $R$ '? Would the addition of the words 'I don't mean close to the river bank, I mean close to the financial institution ten blocks way' count as explicit cancelation of an implicature ? Of course not. This example shows that Grice's characterization of cancelability should be used with care : for a meaning component $m$ carried by an utterance of $F$ to count as 'cancelable', hence as a candidate implicature, it is clearly not enough that one can find situations in which an utterance of $F$ would not carry that meaning component. Grice's cancelability test significantly applies only to forms of words that are not (relevantly) ambiguous ; for ambiguous expressions pass the test for trivial reasons that have nothing to do with implicatures. So, if the form of words we want to apply the test to is ambiguous, we should disambiguate it (i.e. specify the intended reading) before we apply the test and make sure that the expression is taken in the same sense in the original context $c$ and the alternative context $c$ ' in which the alleged implicature disappears.

Now, precisely, an open quotation in the complement clause of a locutionary report is ambiguous, according to Cappelen \& Lepore. That ambiguity is due to the fact that quotation marks are carelessly used both for quoting (their properly semantic function) and for 'scarequoting' (a distinct function with no semantic import). According to Cappelen \& Lepore, scare-quoting has nothing to do with quoting, semantically, so the quotation marks should be treated as ambiguous (or, as they put it, as having a 'dual usage'). Since that is so, the alleged cancelation effected by context in my examples (20) and (21) simply reflects the fact that, by changing the context, we shift the (most salient) reading of the sentence from the quotational reading to the scare-quote reading, just as, by changing the context, we can shift the most salient reading of 'bank' from the river reading to the financial reading. If, before applying the test, we disambiguate the sentence (as we should) and give the quotation marks the quotational reading (both in $c$ and $c^{\prime}$ ), then the entailment turns out to be noncancelable! That is Cappelen \& Lepore's response to my examples. Gomez-Torrente, who agrees with me (against Cappelen \& Lepore) that the mixed-quotational ascription of the quoted words to the reportee is cancelable, agrees with them that my example (20), because it involves scare quotes, 'cannot convince someone who does not accept that all uses of the quotation marks have the same meaning' (Gomez-Torrente 2005: 135).

Before considering the relation between cancelability and ambiguity in some detail, let me first point out that the use of 'scare quotes' in my examples is not essential. What (20) and (21) are meant to illustrate are cases in which the echoee is distinct from the reportee. That the speaker of (20) and (21) is ironically mocking the echoee, or distancing herself from the 
echoee, is an irrelevant feature of the example, which can be removed. In this respect example (19) appears quite different, and I wonder what Cappelen \& Lepore would say about it. ${ }^{19}$

Whoever holds that the use of quotation marks in scare-quoting examples like (20) and (21) has nothing to do with their quotational use in (10) and (17) will have a very hard time defending the same line with respect to the following examples:

(22) Alice said that Clinton is 'smooth', to use her very words.

(23) Alice said that Clinton is 'smooth', as she put it.

(24) Alice said that Clinton is 'smooth', as you would put it.

For it is pretty clear that (22) and (23) are very similar to Cappelen \& Lepore's own example of mixed quotation (17) : the additional words 'to use her very words' or 'as she put it' simply make explicit that the quoted words are ascribed to the reportee. So I don't think Cappelen \& Lepore can deny that the quotation marks function in the same way in (22)-(23) and in (17), (10) or the other examples of mixed quotation. The problem, for them, is that (24) is extremely similar to (23) : the main difference is that the additional phrase contains a second person pronoun instead of a third person pronoun (that is what makes the echoee distinct from the reportee). In a nutshell : (24) is extremely similar to (23) which is extremely similar to (17). No sharp demarcation between two distinct 'readings' or 'usages' of the quotation marks can plausibly be invoked here. Now (19), the example which is supposed to demonstrate the cancelability of the mixed-quotational implication of authorship ${ }^{20}$ - and the possibility of Cappelen \& Lepore's 'impossible' sentence (18) - , is nothing but (24) plus an additional sentence canceling the implication in question! In this case, I think, the 'ambiguity' response is hopeless.

Now I turn to the methodological issue : when and how can we apply the cancelability test ? If a meaning component $m$ is an implicature or (more broadly) a pragmatic suggestion rather than a compositionally determined aspect of semantic content, it's got to be cancelable. Cancelability is a necessary condition for a meaning component to count as pragmatic ; it is not a sufficient condition. So cancelability per se does not establish the pragmatic nature of the meaning component. If a form of words $F$ contains an ambiguous expression that has, say, two readings $m$ and $m$ ', the meaning component $m$ which $F$ carries in some contexts will not be carried in other contexts. In this case $m$ is trivially cancelable. We may decide not to use the term 'cancelability' for this trivial form (as Cappelen \& Lepore and Gomez-Torrente suggest) but nothing hinges on this terminological decision, as long as cancelability is simply taken as a necessary condition, not as a sufficient condition for a meaning component to count as pragmatic. So I will continue to talk of 'cancelability' whenever some meaning component carried by a form of word in a context is not carried by that same form of words in another context. Call this 'prima facie cancelability' if you prefer.

When they used the cancelability argument against the pragmatic account, Cappelen $\&$ Lepore were aware that cancelability is a necessary condition for anything to count as

\footnotetext{
${ }^{19}$ Marga Reimer gives an example like (19), for which she credits Philippe De Brabanter (Reimer 2005 : 180). See also Gomez-Torrente 2005: 135 for a similar example intended to demonstrate cancelability without relying on scare-quoting. Benbaji (2005:35) also mentions the possibility that the echoee might not be the reportee, but strangely shies away from the conclusion that the mixed-quotational implication is cancelable, on the grounds that the conventional implicature/presupposition that someone used the words is not.

${ }^{20}$ I will henceforth use that phrase to refer to the 'entailment' allegedly contributed by the quotation marks in mixed-quotational sentences (to the effect that the reportee used the quoted words in performing the locutionary act $V$ that is being reported).
} 
pragmatically imparted rather than semantically encoded. They argued that the mixedquotational implication of authorship cannot be pragmatic, since it is not cancelable. Their argument relies on two premisses, as we have seen : the first premiss says that a meaning component that is not cancelable is semantic rather than pragmatic; and the second premiss (which I reject) says that the mixed-quotational implication of authorship is not cancelable. To dispose of their argument, it is sufficient to show, as I had done in anticipation, that the implication in question is cancelable : the very form of words, e.g. (17), which carries the implication in certain contexts does not carry the implication in other contexts.

I have, of course, never claimed that the cancelability of the implication was sufficient to establish its pragmatic nature; for, as Cappelen \& Lepore and Gomez-Torrente point out, if the form of words at issue is ambiguous between a reading on which it carries the mixedquotational implication and another reading on which it does not, then the implication will be (prima facie) cancelable but that will not show that it is pragmatic. What cancelability shows is simply that the meaning component as issue could be pragmatic ; but there is another option - ambiguity - that has to be ruled out before we can conclude that it is pragmatic. The cancelability test does not help us choose between the two options. To choose between the two options in that sort of case, Grice used another criterion, which we can appeal to also in the case at hand.

Before proceeding, let me note that the situation is exactly the same in the present case and in the classical cases in which the Gricean criteria have been applied to establish the pragmatic nature of an implication. Consider 'and' and 'or'. The connective 'or' has two prima facie 'readings' : the inclusive reading and the exclusive reading. It may be taken to be ambiguous between the two readings, but it is also possible to take the inclusive reading to be the only 'literal' reading of the connective, and to account for the exclusive 'reading' by positing an implicature that combines with the literal reading in some contexts. On this pragmatic analysis, the two 'readings' are simply : the reading with the implicature (exclusive reading) and the 'plain' reading without the implicature (inclusive reading). Grice similarly argued that 'and' is not ambiguous, i.e. that it has only one literal 'reading' (the logical reading) : the various other 'readings' (the temporal reading, the causal reading, etc.) all result from the addition of an implicature. Now, of course, cancelability cannot be used to disprove the ambiguity analysis ; for if 'or' were ambiguous between the two readings, the exclusivity implication would be prima facie cancelable. Cancelability does not tell us which analysis is right. To establish the pragmatic nature of a meaning component, we must appeal to other features of implicatures, such as Grice's 'nondetachability' and 'calculability'. If a meaning component is not only cancelable but also nondetachable and calculable, it is very unlikely that it is 'semantic' rather than pragmatic.

Be that as it may, the main tool in Grice's hands for showing that a meaning component is pragmatic rather than semantic is the methodological precept he called 'Modified Occam's Razor' : Do not multiply senses beyond necessity (Grice 1989 : 00). ${ }^{21}$ According to that principle, if a given phenomenon (e.g. the two 'readings' of disjunction) can be accounted for either in terms of semantic ambiguity or in terms of implicature, we should choose the account in terms of implicature because it is more parsimonious. Thus Grice argued against the ambiguity of logical particles like 'and' and 'or' between several readings on the grounds that a pragmatic story can be told that posits only an implicature and a basic meaning. Since implicatures are cancelable and appear only in some contexts, the pragmatic story accounts for the existence of two apparent 'readings' : the reading with the implicature and the 'plain' reading without the implicature. Note that, in all such cases, an

${ }^{21}$ See also Kripke's dictum : 'Do not posit an ambiguity unless you are really forced to' (Kripke $1977: 268$ ). 
ambiguity theorist might respond as Cappelen \& Lepore do : that cancelability per se does not disprove the ambiguity thesis. But Grice and the Griceans never claimed that it did. What cancelability (together with the other features) does is show the possibility of a pragmatic explanation. To dispose of the ambiguity thesis, Grice appeals to Modified Occam's Razor. According to Grice, it is less economical to posit an ambiguity, if a pragmatic explanation is available, since the pragmatic story stipulates only one sense (instead of two) and appeals to general and independently motivated principles to account for the generation of the implicature.

It is instructive to look at Kripke's well-known application of the Gricean strategy to the referential/attributive distinction. Kripke argues that the definite article is not ambiguous between two readings, on the grounds that a pragmatic explanation is available. The pragmatic explanation is more parsimonious, for the ingredients it uses are available whether or not one posits an ambiguity. Positing an ambiguity therefore achieves nothing : there are no phenomena that can be explained in the ambiguity framework, and which could not be explained if we did not posit the ambiguity. To show that, Kripke invites us to imagine a language in which the definite article is, by stipulation, univocal and has the Russellian semantics. Definite descriptions will still have 'two uses' in such a language, since the referential use can be accounted for on the basis of the Russellian semantics plus general and independently motivated principles of language use. This thought-experiment strikingly demonstrates that positing an ambiguity adds nothing in terms of explanatory potential (but costs more).

The dialectic with the mixed-quotational implication of authorship is exactly the same. Cappelen \& Lepore accept that the implication is prima facie cancelable, but claim that this results from an ambiguity : the quotation marks mean something different when the implication is absent. The situation is as follows : (1) There are two prima facie 'readings' of sentences of the form ' $x V$ that $p$ ' where the complement sentence contains a sub-clausal open quotation - one reading with the mixed-quotational implication and another reading without it. (2) There are two competing accounts : a semantic account that posits an ambiguity, and a pragmatic account that posits only one basic meaning plus a pragmatic suggestion. (3) The pragmatic account is, as always, more parsimonious. ${ }^{22}$

That the pragmatic story is more parsimonious, and should therefore be preferred, can be shown by following Kripke's procedure and imagining a language in which, by stipulation, there are no 'quotation marks' with a special semantics, but the speaker can still ostensively demonstrate the words she uses while speaking. In some context the demonstration will be understood as a piece of mimicry whereby the speaker echoes some contextually identifiable person. If the piece of mimicry occurs in the complement clause of a sentence reporting the content of someone's speech, the speaker will naturally be understood as mimicking the reportee and speaking like him. (In other words, the echoee and the reportee will be identified.) The demonstrated words - or the tone of voice, or the special pronunciation, or whatever is ostensively demonstrated - will be ascribed to the reportee. In this way it can be shown that the mixed-quotational implication of authorship can be accounted for on pragmatic grounds.

Instead of imagining a language without quotation marks, we can simply look for an utterance of the form ' $x V$ that $p$ ' containing no quotation marks but such that the speaker, while reporting the content of $x$ 's speech, ostensively displays some of the words used in the content clause, and does so with a manifestly echoic intention. The pragmatic theory predicts that, in such circumstances, the mixed-quotational implication that the reportee used those

\footnotetext{
22 Thus Saka rightly criticizes Cappelen \& Lepore's account on the grounds that it 'posit[s] unnecessary ambiguity' (Saka $2005: 203$ ).
} 
words (or this tone of voice, or this special pronunciation, or whatever) will be generated. That this prediction is borne out is shown by this example from Dickens, cited in 'Open Quotation':

(25) To which Mr Bailey modestly replied that he hoped he knowed wot o'clock it wos in gineral. (Dickens, Martin Chuzzlewit, cited in Clark and Gerrig 1990, p. 791)

Here the speaker reports the ascribee's talk, using indirect speech in the normal way, and at the same time shows what the talk was like. The sentence does not contain quotation marks, yet the implication that Mr Bailey spoke this way can easily be derived, simply by asking the following questions :

Q1: Why is the speaker ostensively speaking in this funny way?

Answer: Because he mimicks Mr Bailey.

Q2: Why is he doing so ?

Answer : In order to inform the hearer that that's the way Mr Bailey spoke when he replied.

Since it is mutually manifest to the speaker and the hearer that the hearer can find the answer to Q2, and since the speaker has done nothing to prevent the hearer from reaching that conclusion, the speaker overtly implies, hence communicates (in the Gricean sense of 'nonnatural meaning'), that Mr Bailey spoke this way when he replied. The piece of information thus pragmatically imparted overlaps with the semantic content of the utterance (to the effect that Mr Bailey said such and such) and fuses with it through the mechanism of free enrichment. That is the pragmatic explanation I offer for the phenomenon at issue (the ascription of the special way of speaking to Mr Bailey in this example, the mixed-quotational implication of authorship in the other cases). As always with pragmatic explanations, the main reason for accepting it rather than its semantic rivals is that it is more parsimonious. ${ }^{23}$

\section{References}

Bach, K. 1999: The Myth of Conventional Implicature. Linguistics and Philosophy, 22 : 32766.

Bar-Hillel, Y. 1954: Indexical Expressions. Reprinted in his Aspects of Language, Jerusalem: Magnes Press, 1970, pp. 69-88.

Benbaji, Y. 2004 : Using Others' Words. Journal of Philosophical Research 29 : 93-112.

Benbaji, Y. 2005 : Who Needs Semantics of Quotation Marks ? Belgian Journal of Linguistics $17: 27-50$

Cappelen, H. and Lepore, E. 2005 : Varieties of Quotation Revisited. Belgian Journal of Linguistics $17: 51-76$

— 2007 : Language Turned Upon Itself. Oxford : Oxford University Press.

Clark, H. and Gerrig, R. 1990: Quotations as Demonstrations. Language, 66 : 764-805.

De Brabanter, P. (ed.) 2005. Hybrid Quotations. Amsterdam : John Benjamins (= Belgian Journal of Linguistics 17, 2003).

Garcia-Carpintero, M. 2005 : Double-Duty Quotation: The Deferred Ostension Account. Belgian Journal of Linguistics $17: 89-108$.

Geurts, B. and Maier, B. 2005 : Quotation in Context. Belgian Journal of Linguistics 17 : 109-128.

\footnotetext{
${ }^{23}$ I am grateful to CSMN for financial support
} 
Gomez-Torrente, M. 2005 : Remarks on Impure Quotation. Belgian Journal of Linguistics $17: 129-152$.

Grice, P. 1989 : Studies in the Way of Words. Cambridge, Mass. : Harvard University Press. Kripke, S. 1977 : Speaker's Reference and Semantic Reference. Midwest Studies in Philosophy 2 : 255-76.

Levinson, S. 2000 : Presumptive Meanings. Cambridge, Mass. : MIT Press.

Neale, S. 1999: Coloring and Composition. In K. Murasugi and R. Stainton (eds.), Philosophy and Linguistics, Boulder: Westview, pp. 35-82.

Potts, C. 2005 : The Logic of Conventional Implicatures. Oxford : Oxford University Press.

- 2007 : The Dimensions of Quotation. In C. Barker and P. Jacobson (eds.), Direct Compositionality, Oxford: Oxford University Press, pp. 405-431.

Predelli, S. 2003 : Scare Quotes and Their Relation to Other Semantic Issues. Linguistics and Philosophy $26: 1-28$.

— 2005a : Contexts : Meaning, Truth, and the Use of Language. Oxford : Oxford University Press.

— 2005b : 'Subliminable' Messages, Scare Quotes, and the Use Hypothesis. Belgian Journal of Linguistics 17 : 153-166.

Recanati, F. 1979: La Transparence et l'Enonciation. Paris: Editions du Seuil.

- 1997: Can We Believe What We Do Not Understand ? Mind and Language 12 : 84-100.

- 1998: Pragmatics. In E. Craig (ed.), Routledge Encyclopedia of Philosophy.

- 2000: Oratio Obliqua, Oratio Recta: An Essay on Metarepresentation. Cambridge, Mass: MIT Press/Bradford Books.

— 2001: Open Quotation. Mind 110:637-687.

- 2004 : Literal Meaning. Cambridge : Cambridge University Press.

Reimer, M. 2005 : Too Counter-Intuitive to Believe ? Pragmatic Accounts of Mixed

Quotation. Belgian Journal of Linguistics 17 : 167-86.

Saka, P. 2005 : Quotational Constructions. Belgian Journal of Linguistics 17 : 187-212.

Sperber, D. and D. Wilson 1981: Irony and the use-mention distinction. In P. Cole (ed.), Radical Pragmatics, New York: Academic Press, pp. 295-318.

- 1986: Relevance: Communication and Cognition. Oxford: Blackwell. 